\title{
DA UNIVERSIDADE AO MERCADO: O MOVIMENTO ESTUDANTIL NA CONSOLIDAÇÃO DE UMA IDENTIDADE DE CLASSE.
}

\section{UNIVERSITY OF THE MARKET: THE STUDENT MOVEMENT IN THE CONSOLIDATION OF A CLASS OF IDENTITY.}

\section{Rosimeri Ferraz Sabino}

Mestre em Educação, Administração e Comunicação pela Universidade São Marcos Professora Assistente da Universidade Federal de Sergipe - UFS E-mail: rf.sabino@gmail.com (Brasil) 


\title{
DA UNIVERSIDADE AO MERCADO: O MOVIMENTO ESTUDANTIL NA CONSOLIDAÇÃO DE UMA IDENTIDADE DE CLASSE.
}

\begin{abstract}
RESUMO
Neste trabalho analisa-se o movimento estudantil do curso de Secretariado Executivo da Universidade Federal de Sergipe, com o objetivo de verificar como tal movimento relaciona-se à construção da identidade profissional e ao consequente fortalecimento da classe secretarial sergipana. Buscou-se identificar como ocorre o movimento estudantil no curso, verificando a percepção dos estudantes sobre o atual estágio da profissão de secretário em Sergipe e analisando as ações e os resultados do movimento para a consolidação identitária da classe profissional. Como instrumento da técnica de estudo de caso foi utilizado um questionário distribuído a estudantes do curso com matrículas ativas até o primeiro semestre de 2013. Os dados obtidos foram analisados sob a luz da história cultural, no tocante à construção identitária, e da sociologia das profissões. Constatou-se que o movimento estudantil do curso se mostra forte agente nas ações de construção identitária da profissão no mercado, principalmente pelo fato de ser constituído na única formação em nível superior oferecida no Estado. No tripé do sistema de credencialismo profissional: entidades representantes, Estado e profissionais, os estudantes do curso da UFS parecem ser os agentes mais ativos na busca de reconhecimento na sociedade, comprovando-se, assim, que a cultura universitária em seus movimentos estudantis corroboram a construção da identidade profissional do futuro egresso.
\end{abstract}

Palavras-chaves: Movimento Estudantil; Processos Identitários; Profissões; Secretariado.

\section{UNIVERSITY OF THE MARKET: THE STUDENT MOVEMENT IN THE CONSOLIDATION OF A CLASS OF IDENTITY.}

\begin{abstract}
This work analyze the student movement of course Executive Secretariat of the Federal University at Sergipe, in order to see how such movement is related to the construction of professional identity and the consequent strengthening of the class secretarial. Sought to identify how the student movement occurs in the course, checking the students' perception of the current state of the profession of secretary in Sergipe and analyzing the actions and results of the movement to consolidate identity of the professional class. As an instrument of technical case study used a questionnaire distributed to students with registrations active until the first half of 2013. The data were analyzed approach under of cultural history, on the construction of identity, and sociology of the professions. It was found that the student movement is the strong agent in the actions of identity construction the profession in the market, mainly because it's constituted in one course university degree offered in the state. In the system professional credentialism: entities representatives, state and professionals, students of the UFS seem to be the most active agents in seeking recognition in society, proving thus that the university culture in their student movements corroborate the professional identity of future graduates.
\end{abstract}

Keywords: Student Movement; Identity Processes; Professions; Secretariat. 


\section{INTRODUÇÃO}

O tema educação e trabalho remete à imbricação das ações dos agentes formadores e daqueles que são formados para resultados na inclusão do egresso na vida produtiva da sociedade. Os questionamentos a um reducionismo da educação ao pragmatismo ou tecnicismo encontram oposições nas discussões do papel da educação diante dos objetivos de desenvolvimento social. Tal desenvolvimento depende de conhecimentos e reflexão cunhados ou, no mínimo, incentivados no âmbito educacional. As mudanças culturais, políticas e econômicas da sociedade pós-moderna instituíram relações globalizadas que implicam a reestruturação produtiva e, por consequência, no mercado de trabalho. Esse contexto conduz à necessidade de ajustamento de perfis profissionais diante da cognição, técnicas e comportamentos, resultando em recursos humanos adequados às competências necessárias apontadas pelas organizações empregadoras (Rosa, 1990).

Como instituições formadoras, as universidades constam como agentes desse processo preparatório do indivíduo para o seu ingresso nas relações produtivas. O estudante, por sua vez, passa a viver a cultura universitária, em que ocorrem as socializações que formam a sua identidade profissional (Godim, 2002). Entenda-se, aqui, que a concepção de profissão está relacionada a estatutos que diferenciam as atividades entre ofícios. Os estudantes universitários, portanto, vêemse sendo qualificado para compor um grupo de profissionais de atividades regulamentadas, passando a compor uma identidade coletiva.

Nesse sentido, a experiência inicial de um grupo de estudantes de determinado curso universitário em busca de uma identidade coletiva no ambiente acadêmico é, pois, a sua organização em uma representação estudantil. No Brasil, a primeira manifestação estudantil remonta a 1710, sobre a expulsão de franceses no Rio de Janeiro (Poerner, 1979). Desde a primeira escola de ensino superior criada no Brasil, em 1808, com o curso de Medicina, os estudantes organizam as suas representações. Como exemplo, têm-se o primeiro Centro Acadêmico de Direito, da Faculdade de Direto do Largo de São Francisco (USP), criado em 1903 (Centro Acadêmico XI de Agosto, 2013). Porém, a organização estudantil formal, em nível nacional, ocorreu em 1937, com a criação da União Nacional dos Estudantes (UNE) (Freitas, Souza, 2012). Como parte da estrutura do movimento estudantil, constam os centros e diretórios acadêmicos, os primeiros representando um curso e os segundos, representando mais de um.

Neste trabalho analisa-se o movimento estudantil do curso de Secretariado Executivo da Universidade Federal de Sergipe, com o objetivo de verificar como tal movimento relaciona-se à construção da identidade profissional e ao consequente fortalecimento da classe secretarial

Revista de Gestão e Secretariado - GeSec, São Paulo, v. 4, n. 3, p 58-82, dez. 2013. 
sergipana. Buscou-se identificar como ocorre o movimento estudantil no curso, verificando a percepção dos estudantes sobre o atual estágio da profissão de secretário em Sergipe e analisando as ações e os resultados do movimento para a consolidação identitária da classe profissional.

A abordagem para as análises partem dos trabalhos de Pierre Bourdieu, Stuart Hall, Eliot Freidson e Claude Dubar. Como instrumento de técnica da pesquisa foi utilizado um questionário distribuído a estudantes do curso de Secretariado Executivo da Universidade Federal de Sergipe, com matrículas ativas até o primeiro semestre de 2013. Os dados obtidos foram analisados sob a luz da história cultural e da sociologia das profissões.

\section{REFERENCIAL TEÓRICO}

O movimento estudantil no mundo surge como coletivo para a inclusão de estudantes nas discussões políticas sobre as condições de ensino e demais causas sociais que afetassem esse público, o qual se via envolvido também como cidadão na sociedade (Poerner, 1979). Em épocas de conflitos políticos, esse movimento surge com ênfase, participando em várias esferas de discussões e, em momentos de repressão, é alvo de políticas silenciadoras para evitar qualquer desequilíbrio na obtenção das intenções dos que estão no comando. Em narrativa histórica sobre as ações dos estudantes brasileiros, consta:

\footnotetext{
No Brasil, a importância do movimento estudantil acompanha a trajetória de sua entidade máxima, a UNE [...]. Mesmo quando a entidade foi fechada pela ditadura militar, os estudantes saíam às ruas declarando que, enquanto estivessem lutando, a UNE estaria viva; porque a UNE era nada mais nada menos do que eles próprios atuando politicamente. Este era o sentido da palavra de ordem dos anos 1970 e 1980: "A UNE somos nós, nossa força e nossa voz". (Araújo, 2007, p. 18)
}

No entanto, como campo social, o movimento estudantil é também um espaço de forças e embates internos por solicitações de seus membros pela sua transformação ou conservação. Conforme Bourdieu (1997, p. 27), “Os campos são os lugares de relações de forças que implicam tendências imanentes e probabilidades objetivas". Disso se depreende que os membros constituintes desse movimento mesmo com divergências internas, buscam manter a identidade coletiva, sob um grau de autonomia que os tornem capazes de enfrentar as pressões que os envolvem e obterem as suas reivindicações. 
Assim, além do objetivo de ações relacionadas às discussões sobre temas sociais gerais, o movimento estudantil volta-se, igualmente, para a reflexão sobre a qualidade de uma formação, capaz de inserir os estudantes na vida produtiva, sob uma visão de preparação para a cidadania e possibilidade de enfrentamento dos desafios do mercado. As políticas educacionais internas das instituições, dessa forma, tornam-se espaços necessários para as discussões dos estudantes (Rosa, 1990).

No Brasil, a partir do surgimento da UNE, em 1937, surgiram as organizações estudantis em centros e diretórios acadêmicos no ensino superior. As discussões estudantis atuais divergem entre um ensino universitário não voltado especificamente às demandas de mercado, e os que defendem uma educação superior capaz de se inter-relacionar com as necessidades empresariais. $O$ ponto de convergência parece residir na intenção de intervenções educacionais que representem efetivo desenvolvimento ao país através de recursos humanos qualificados (Carvalho, 2000).

Não obstante a qualquer polêmica, o acesso a uma educação superior é frequentemente interpretado como possibilidade de ascensão social (Rosa, 1990). No aprendizado de uma profissão, o indivíduo vislumbra pertencer a um grupo específico que atuará sob conhecimentos formalmente organizados para o desempenho na sociedade. Dessa forma, sairá ele do campo estudantil para o campo profissional, indo para um ambiente de ação diverso, mas sob a construção identitária constituída em sua trajetória de formação. Adotando-se a concepção do sujeito sociológico: “a identidade é formada na 'interação' entre o eu e a sociedade. O sujeito ainda tem um núcleo ou essência interior que é o 'eu real', mas este é formado e modificado num diálogo contínuo com os mundos culturais ‘exteriores' e as identidades que esses mundos oferecem”. (Hall, 2005, p. 11).

Dessa forma, o estudante universitário torna-se, durante a sua formação, constituído pela cultura universitária no que concerne aos aspectos de tradição da profissão para a qual está se preparando. Quando egresso, a sua identidade sofre a tradução do aprendiz para o profissional, mas não abandonando as "raízes" identitárias assimiladas durante o tempo nos bancos acadêmicos (Hall, 2005). A experiência acadêmica, envolvendo conhecimentos, técnicas e comportamentos para determinada profissão, resulta em consciência sobre a própria profissão (Thompson, 1981). Nesse sentido, as ações de um movimento estudantil em seu viés crítico e politizado que constituem o embrião da defesa de um campo profissional, ao tempo em que coloca os estudantes diante das condições de ensino e da realidade social em que tal ensino poderá contribuir.

Revista de Gestão e Secretariado - GeSec, São Paulo, v. 4, n. 3, p 58-82, dez. 2013. 


\subsection{DA EDUCAÇÃO AO CREDENCIAMENTO PROFISSIONAL}

Os embates sobre os objetivos da educação são cotidianamente expostos, recebendo defesas, inclusive, de que são eles necessários para a própria evolução da sociedade. No tocante à educação superior, a Lei de Diretrizes e Bases para a Educação no Brasil (1996), menciona como uma de suas finalidades: "formar diplomados nas diferentes áreas de conhecimento, aptos para a inserção em setores profissionais e para a participação no desenvolvimento da sociedade brasileira, e colaborar na sua formação contínua" (grifo nosso).

Resta claro, portanto, que um curso superior habilita o indivíduo para o profissionalismo, termo que demanda a compreensão de distinções diante da sociologia das profissões. Antes da existência das universidades, tornar-se profissional significava fazer parte de uma corporação de ofício, entendido como uma atividade que demandava conhecimentos especializados, voltados especialmente para as artes e que exigiam juramentos para a guarda de tais conhecimentos como forma de defender o monopólio e privilégios dos que usufruíam do status profissional (Dubar, 1997).

Modernamente, entende-se que a validade de uma profissão baseia-se em um sistema abrangente de conhecimentos científicos e suas aplicações, detidos entre os membros que a constituem e tornando-a uma posição privilegiada dentre as ocupações em geral. A aquisição e a posse desses conhecimentos estão sujeitos a certas condições, e têm efeitos que constituem fatores importantes no estabelecimento de uma profissão. Uma das mais importantes dessas condições é que os conhecimentos são adquiridos a partir de colegiados universitários, os quais geram, transmitem e sistematizam o corpo conceitual e a práxis para os futuros novos membros da profissão. Assim, as universidades são a fonte da autoridade científica na área da profissão, possuindo o poder sobre a definição de conteúdo, emitindo opinião e dirimindo eventuais dúvidas e/ou conflitos sobre a área. Essas instituições, junto com as associações profissionais e o Estado, compõem o sistema de credenciamento descrito por Eliot Freidson (1998), crítico da visão funcionalista sobre as profissões.

Já para Larson (1977), o controle do mercado de serviços profissionais está ligado ao potencial da aplicação do conhecimento abstrato na prática controlada pela profissão, favorecendo, assim, a manutenção de um monopólio de competência. Os elementos que levam a esse monopólio são: a natureza do serviço que é oferecido; o tipo de mercado; o tipo de clientela; a base cognitiva 
(científica); a formação profissional; as relações de poder, e a afinidade com a ideologia dominante.

Para Johnson (1972), uma profissão é o controle político do trabalho por determinado grupo, sob o apoio do Estado, se tornando, assim, elemento de poder. A autonomia de uma profissão não provém apenas do conhecimento, mas do conjunto de jurisdição que garante o monopólio de seu exercício. Compartilhando a visão sobre juridicação, Abbott (1988) propõe que o foco de análise sobre as profissões seja as disputas jurisdicionais e os processos de ampliação ou redução dessas jurisdições.

Esses autores constituem a escola revisionista da sociologia das profissões, caracterizada pela diversidade teórica e pela oposição à ideologia do profissionalismo. Para os autores desse movimento, a profissão é um grupo com uma função especial, baseada em um aprendizado extenso e em um conhecimento abstrato. Abandona-se, assim, a visão da profissionalização como um processo natural, adotando-se a análise e valorização das relações das profissões com a estrutura social, as organizações e a política. Passou-se a examinar o conhecimento abstrato como monopólio do poder e privilégio, analisando e discutindo não mais a forma, mas as funções da profissionalização.

Essa visão sucede as versões da teoria funcionalista que consideram as profissões elementos essenciais da estrutura social. Já sob o enfoque dos autores da escola de Chicago, entre eles Everett Cherrington Hughes (1981), Leonard Anselm Strauss (1992) e Howard Becker (1970), as profissões não são entidades, mas, sim, movimentos permanentes de construção e desconstrução de segmentos profissionais diante de exigências de competências e situações de conflito, tornando-se processos sociais. Esses teóricos entendem que o ofício de uma pessoa é um dos componentes mais importantes de sua identidade social, de si mesma e, inclusive, de seu destino, implicando, portanto, na existência pessoal e na vida social.

As teorias das décadas de 1970 e 1980 consideram a dinâmica histórica das profissões dentro da economia, analisando as relações entre Estado, mercado e profissões, combinando perspectivas interacionistas e funcionalistas. Isso significa que a sociologia das profissões se manifesta sob vários paradigmas, submetida a permanentes análises sob diferentes pontos de vista. Assim, o estudo das profissões impõe a combinação de conceitos, razões, métodos e técnicas de tradições teóricas diversas.

Os estudos contemporâneos sobre profissões tendem a empregar aspectos da teoria das organizações. Para Abbott (1988), as mudanças profissionais ocorrem através de disputas interprofissionais, impondo o estudo das suas organizações associativas. Já Freidson (1998) salienta o papel do conhecimento especializado e as rotinas profissionais, aspectos que exigem empenho dos

Revista de Gestão e Secretariado - GeSec, São Paulo, v. 4, n. 3, p 58-82, dez. 2013. 
sociólogos para a análise do comportamento dos profissionais nas organizações complexas. Assim, observa-se a aproximação entre sociologia das profissões, as teorias das organizações e a educação, a qual é o espaço inicial de formação do sistema de credenciamento de uma profissão.

\subsection{O MOVIMENTO DO CAMPO DA EDUCAÇÃO PARA O CAMPO PROFISSIONAL}

Assumindo-se a visão funcionalista sobre as profissões de que elas formam "comunidades reunidas à volta dos mesmos valores e da mesma 'ética de serviço', tendo um estatuto profissional validado por um saber científico" (Dubar, 1997, p. 131), considera-se o movimento estudantil constituído nas ações de um centro acadêmico como uma comunidade embrionária da defesa dos valores que coadunam com um órgão representante da profissão no mercado de trabalho. Afinal, as traduções operatórias da cultura universitária de uma determinada formação para profissão regulamentada irão auxiliar no funcionamento e legitimação do campo profissional. De membro aspirante a uma profissão, o estudante universitário passará a compor uma construção social, a profissão, que conforme Bourdieu (1989, p. 40) "é produto de todo um trabalho social de construção de um grupo e de uma representação dos grupos".

Dessa forma, um centro acadêmico configura-se espaço que se erige como representação e, como tal, compartilha interesses de defesa do campo profissional no mercado de trabalho. Assim, analisando-se nesta investigação o Centro Acadêmico de Secretariado Executivo Maria Lúcia Souza dos Prazeres (Case-MLSP), da Universidade Federal de Sergipe, retoma-se a sua história na instituição.

O curso de Secretariado Executivo na citada universidade foi criado em 30 de agosto de 2006 (Resolução 41/CONSU), como resultado dos pleitos do Sindicato das Secretárias e Secretários do Estado de Sergipe [SINSESE] junto à Universidade, através do Centro de Ciências Sociais e Aplicadas [CCSA], visando o atendimento à demanda de profissionais da área nas organizações sergipanas. Esse processo teve como participantes centrais o Prof. Dr. Napoleão dos Santos Queiroz, então, Diretor do CCSA, e a Sra. Maria Lúcia Souza dos Prazeres, Presidente do SINSESE. Pela inclusão do curso no plano de expansão da instituição, a formação teve o primeiro vestibular em janeiro de 2007, com 50 ingressantes, sendo 6 homens e 44 mulheres. O curso permanece sendo o único em nível de bacharelado presencial oferecido no Estado.

O corpo docente do curso foi constituído, inicialmente, por professores não especialistas na 
área, constando os primeiros professores com formação específica apenas a partir da segunda metade do ano de 2008. Da constituição atual de sete docentes, apenas três são oriundos do Secretariado. Esse aspecto torna-se relevante já que os agentes formadores configuram-se constituintes da identidade profissional, uma vez que interagem com os alunos através de ações significantes aos sentidos da formação identitária (Williams, 2008).

A representação estudantil do curso constituiu-se a partir da Assembleia Geral dos alunos, ocorrida em 12 de dezembro de 2007. Esse encontro viabilizou a formalização do Centro Acadêmico de Secretariado Executivo [CASE], em 12 de abril de 2008. Entre os estudantes pioneiros na organização da representação dos discentes constaram oito alunas: Ana Carla de Lima, Ana Cely Moura dos Santos, Ana Luiza Gomes de Oliveira Silva, Camila de Santa Silva, Laís Brito Guedes, Maria Isabel Silva Pereira Moura, Valquíria Dantas de Góes e Tiara Câmera da Silva. A entidade prevê como objetivos, no artigo $3^{\circ}$ de seu estatuto:

\footnotetext{
I - Reconhecer, estimular e levar adiante a luta dos estudantes do Curso de Secretariado Executivo da Universidade Federal de Sergipe - UFS, em defesa de seus interesses. II - Organizar os estudantes de Secretário Executivo na luta por uma Universidade crítica, autônoma e democrática, bem como ao lado do povo, para a construção de uma sociedade livre, democrática, sem exploração e sustentável;

III - Lutar pela ampliação da participação da representação estudantil nos órgãos colegiados;

IV - Estimular e defender qualquer tipo de movimento ou organização democrática autônoma que estejam orientados no sentido dos objetivos que constam deste estatuto. (Case,2008)
}

Percebe-se nos objetivos estatutários que a representação estudantil do curso alia-se a movimentos de defesa da formação, o que conduz a representações além do ambiente universitário. No mercado de trabalho, a representação dos secretários sergipanos é feita através do Sindicato das Secretárias e Secretários do Estado de Sergipe [SINSESE]. Essa entidade prevê em seu estatuto, artigo $4^{\circ}$, as seguintes finalidades:

a) representar, perante as autoridades administrativas e judiciárias os interesses gerais da categoria e os interesses individuais dos associados, relativos a profissão, inclusive na qualidade de substituto processual;

b) celebrar contratos coletivos de trabalho e defender os interesses das Secretárias/Secretários nos dissídios que envolvam a sua condição profissional.

c) fiscalizar as condições de exercício profissional, fazendo cumprir as disposições legais que regulamentam a profissão. (SINSESE, 1991).

Já em nível nacional, os estudantes sergipanos, futuros profissionais, recebem a representação da Federação Nacional das Secretárias e Secretários [FENASSEC], que no artigo $3^{\circ}$,

Revista de Gestão e Secretariado - GeSec, São Paulo, v. 4, n. 3, p 58-82, dez. 2013. 
alínea "l" de seu estatuto, prevê como dever da entidade: "colaborar com os órgãos competentes na criação e/ou melhoria dos cursos de formação, qualificação, aperfeiçoamento, complementação, e extensão inerentes à profissão.” (FENASSEC, 2010).

Constata-se, assim, que o movimento estudantil, próprio da cultura universitária, nos casos de profissões regulamentadas como a do secretário executivo (Leis 7.377/85 e 9.261/96) recebe a possibilidade de se traduzir em outros movimentos, como os de classe profissional. Evidencia-se que a intenção desde o ambiente acadêmico é a defesa dos interesses de um grupo específico, no esforço de constituir a sua identidade nas instituições, grupos ou sociedade em que está presente. Assim, diante da concepção sociológica, a identidade resultaria da internalização de significados e valores projetados durante a formação, alinhando sentimentos subjetivos aos lugares objetivos que o indivíduo ocupará no mundo social e cultural (Hall, 2005).

$\mathrm{Na}$ verificação das ações estudantis do curso, identificou-se uma lacuna de registros sistematizados entre os anos de abril de 2009 a abril de 2012, o que exigiu a busca de informações sobre ações que constassem a representação do Centro Acadêmico. Identificou-se o apoio da representação, em outubro de 2009, em ato acerca de consulta pública do Ministério da Educação sobre a extinção do título de Bacharel em Secretariado Executivo, através de texto subscrito pelos docentes do curso, direção do Centro de Ciências Sociais Aplicadas (CCSA) e Pró-Reitoria de Graduação. Neste documento, constou como presidência do Centro Acadêmico a aluna Ana Luiza Gomes de Oliveira Silva. Em outro documento, datado de 25 de novembro de 2011, tratando-se de um manifesto aberto sobre posição contrária à ocupação de cargo de direção de entidade científica da área por indivíduos com outras formações, constou como presidente da entidade a aluna Emilly Fernanda Pereira Lima dos Santos.

Dada a estrutura colegiada da instituição de ensino, encontra-se registro da presença de alunos como representantes discentes nos anos de 2010, 2011 e 2012 em reuniões do curso, porém não há menção de que se trata de membros do Centro Acadêmico. Cabe ainda ressaltar que as normativas da instituição deixam claro que representantes discentes para participação em conselhos do curso devem ser eleitos pelos alunos, não vinculando nem condicionando as suas presenças em reuniões de conselhos colegiados ao fato de comporem a representação estudantil. Assim, restringiu-se esta investigação às ações dos membros reconhecidamente representantes do movimento estudantil do curso, através da participação no Centro Acadêmico.

Em 4 de abril de 2012, ocorreu o primeiro debate entre duas chapas concorrentes para o 
Centro Acadêmico na gestão 2012/2013. O debate, marco no movimento estudantil do curso, foi conduzido pela comissão eleitoral composta por Fernanda Batista Almeida, Jeize dos Santos Trindade, Katiane da Conceição e Taciane Carvalho Santos. Essa ação foi noticiada como demonstração dos alunos “de maturidade em ações políticas” (Jornal do Dia, 2012, p. 12). A chapa eleita, Fênix, foi composta pelos alunos: Cláudia Santos da Penha, Daniela Araújo dos Santos, Fabrício de Oliveira Aquino, Nívea Maria Souza Araújo, José Alexandre Silva de Brito, Josenilton Nascimento dos Santos, Jossimário de Souza Mick, Omar Pinto Monteiro, Sheila Pereira da Mota, Wanessa Hipólito dos Reis. Consta, ainda, a substituição de alguns membros ao longo da gestão, iniciada em 20 de abril de 2012 e finalizada em 30 de junho de 2013.

Essa gestão foi a primeira a compor um relatório de suas ações, o qual subsidiou esta investigação. Consta como primeira ação da gestão, já em 28 de abril de 2012, a participação no I Encontro de Entidades Representativas de Secretariado em Sergipe, buscando a integração entre o SINSESE e a Empresa Júnior do curso, atualmente extinta. Observa-se, aqui, a busca da integração da identidade dos estudantes ao mundo da profissão (Hall, 2005).

As articulações políticas, que fazem parte do perfil de um movimento estudantil, proporcionou à gestão Fênix a busca e obtenção da criação da Lei Estadual nº 7.393, de 30 de maio de 2012, que instituiu o Dia Estadual do Secretário no Estado de Sergipe. Identifica-se, assim, a significação de pertença ao grupo profissional, ainda enquanto estudantes. É possível, portanto, inferir sobre a presença do diálogo entre o movimento estudantil e o de classe, gerado na construção identitária no mundo acadêmico.

A representação estudantil Fênix, juntamente com alunos, participou em junho de 2012 da organização da XX Conferência Distrital do Rotaract Clubs, suscitando a busca de um reconhecimento sobre um saber legitimado, neste caso a organização de eventos, para o qual estavam se formando (Dubar, 1997). Essa ação reveste-se de uma intenção de significação das práticas secretariais na sociedade (Williams, 2008).

Ainda nessa gestão, em julho de 2012 a representação estudantil atuou na defesa de retificação de edital de concurso para o cargo de secretário executivo na própria instituição de ensino superior, unindo-se para o pleito ao sindicato da categoria sergipana. Evidencia-se, assim, a articulação do movimento estudantil junto ao agente representante para a defesa do campo profissional. Em continuidade, a gestão participou da organização do VII Seminário Interativo de Profissionais e Estudantes de Secretariado, em setembro de 2012, em parceria com o SINSESE, com o objetivo de "comemoração do Dia do Secretário, através da integração entre os discentes e profissionais de Secretariado, abrangendo temas da atualidade relacionados a área secretarial"

Revista de Gestão e Secretariado - GeSec, São Paulo, v. 4, n. 3, p 58-82, dez. 2013. 
(CASE-MLSP, 2013).

A evidência da busca pela consolidação de uma identidade profissional que expande a tentativa do reconhecimento do grupo estudantil na sociedade, comprovando, assim, a formação do sujeito coletivo ainda na formação profissional é encontrada na ação da gestão Fênix, em março de 2013, promovida com o objetivo de mudança do nome da entidade. Com o "objetivo principal [de] homenagear um profissional de Secretariado que fosse engajado na luta pelo reconhecimento e consolidação da profissão" [CASE/MLSP, 2013), em assembléia geral os estudantes elegeram o nome Centro Acadêmico de Secretariado Executivo Maria Lúcia Souza dos Prazeres. Esta eleição foi organizada a partir de um painel de apresentação de três nomes ícones do Secretariado no Brasil, sendo escolhida a secretária executiva Maria Lúcia, ex-presidente do SINSESE. Isto tornou a entidade a primeira no Brasil a se reconhecer em membro da própria classe profissional, ato que remete à associação do sujeito acadêmico ao profissional e à intenção de pertença ao grupo secretarial no mercado de trabalho.

Na finalização da gestão Fênix, constam aspirações da representação para a futura gestão, mencionando: manutenção dos registros históricos da entidade, intensificação da comunicação entre discentes, articulação política para o reconhecimento do Secretariado, articulação pública para aberta de postos de estágios, consolidação da já iniciada reformulação estatuária e conquista de sede. Percebe-se, assim, que a gestão visa àa continuidade em ações de estruturação e evolução da profissão, coadunando com os objetivos de quem os representa no mercado de trabalho. Buscando o estudante ser um profissional de Secretariado, ele obtém “o seu poder a partir da relação com o saber (técnico e especializado) e a sua legitimidade da sua posição individual e coletiva na organização e no mercado de trabalho" (Dubar, 1997, p. 147). Assim, evidencia-se a conexão entre as ações de um movimento estudantil e de uma entidade de representação profissional no processo de consolidação de uma profissão.

\section{METODOLOGIA}

Os procedimentos metodológicos para a investigação assumiram os pressupostos da pesquisa exploratória e descritiva sobre o fato "movimento estudantil" no curso de Secretariado Executivo da UFS, desejando "conhecer a sua natureza, sua composição, processos que o 
constituem ou nele se realizam (Rudio, 2010, p. 71). Essa tipologia de investigação permite “conhecer as diversas situações e relações que ocorrem na vida social, política, econômica de demais aspectos do comportamento humano, tanto do indivíduo tomado isoladamente como de grupos e comunidades mais complexas" (Cervo, Bervian, 1996, p. 56). Pelo enfoque que se pretendeu atingir no tema investigado, adotou-se a técnica de estudo de caso, tendo em vista que a pesquisa "se concentra no estudo de um caso particular, considerado representativo de um conjunto de casos análogos, por ele significativamente representativo (Severino, 2009). Têm-se, ainda, a definição de André para essa técnica como a que pretende "retratar o idiossincrático e o particular como legítimos em si mesmos" e, ainda que "enfatiza a compreensão dos eventos particulares (casos)." (1984, p. 51). O estudo de caso, conforme Yin (2001) torna-se uma metodologia válida em questões que visam responder "como" um fenômeno ocorre, inserido no contexto da vida real, entendido aqui o fenômeno como o fato "tal como é percebido por alguém” (Rudio, 2010, p. 11).

O estudo se classifica como qualitativo em sua abordagem, analisando os dados obtidos sob uma perspectiva dialética com os pressupostos da história cultural e sociologia das profissões e a interpretação sobre as relações entre a realidade acadêmica e profissional dos investigados (Weller, Pfaff, 2010). As interpretações sobre fatos/fenômenos é sustentada no argumento de que "a realidade é socialmente construída por meio de definições individuais e coletivas da situação" (Gamboa, Santos Filho, 1995, p. 39). Portanto, a forma como ocorre o movimento estudantil no curso de Secretariado é construída pelos alunos, em suas percepções individuais e coletivas, relacionando-as às condições em que se definirão no mercado de trabalho.

A pesquisa considerou como fontes documentos do curso de Secretariado Executivo, do SINSESE, da FENASSEC e do CASE-MLSP, além de utilizar como instrumento um questionário aplicado aos alunos com matrículas ativas no curso, até o primeiro semestre de 2013. O instrumento foi elaborado com quinze questões, sendo doze fechadas, uma aberta e duas semiabertas. As questões foram divididas em três blocos, sendo o primeiro com o objetivo de averiguar a visão dos discentes sobre o papel e atuação do Centro Acadêmico; o segundo, com a intenção de identificar a percepção dos alunos sobre o atual estágio da profissão em Sergipe e o terceiro bloco conteve questões para a verificação do envolvimento do estudante com as causas estudantis e profissionais do Secretariado. O tratamento dos dados obtidos foi procedido de forma quantitativa, considerando que as estatísticas podem representar considerável reforço às conclusões do estudo (Gil, 2008).

Revista de Gestão e Secretariado - GeSec, São Paulo, v. 4, n. 3, p 58-82, dez. 2013. 


\section{ANÁLISE E DISCUSSÃO DOS RESULTADOS}

$\mathrm{Na}$ busca de uma estrutura relacional e cultural entre o mundo acadêmico e o do trabalho, a análise priorizou o aspecto sociocultural, no tocante à formação da identidade no sujeito a partir da interação na sociedade, servindo ela como elemento das relações entre o indivíduo e o mundo exterior. Nesse sentido, analisou-se o ambiente de formação como o "exterior" que poderia contribuir em uma concepção interativa com a construção da identidade de futuro profissional de Secretariado, através das experiências compartilhadas com o movimento estudantil do curso. Sobre a profissão, encontrou-se embasamento no sistema de credenciamento de Freidson (1998), onde os agentes formadores, representantes e reguladores constituem um campo profissional, no sentido de Bourdieu (1989), o que permitiu considerar na investigação a entidade representante, o Estado, e os próprios alunos como futuros profissionais do campo.

Como subsídio às análises buscou-se caracterizar o sujeito da pesquisa, em um universo de 235 matriculados no primeiro semestre de 2013, sendo obtidos 129 respondentes, compondo uma amostra de 54,89\% dos alunos, dos quais 104 são mulheres e 25 são homens. Observou-se que o movimento estudantil no curso recebeu maior impulso a partir de 2011, com reivindicações que culminaram no primeiro debate entre chapas concorrentes no início de 2012. Em 2011 também ocorreu a entrada de maior número de homens. De 2007 a 2012 ingressaram na formação da UFS 38 homens, sendo 10 deles no ano de 2011. Entre os atuais matriculados 83,82\% são mulheres e $16,17 \%$ são homens.

A faixa etária das alunas respondentes concentrou-se entre 22 e 26 anos, enquanto a dos homens dividiu-se entre 17 e 21 anos e 22 e 26 anos, o que os designa como membros da geração Y, conforme o período de gerações elaborado por Lancaster e Stillman (2011), para os nascidos entre os anos de 1982 e 2000. Dado que essa geração cresceu em meio a tecnologias e comunicações instantâneas, os indivíduos buscam inovações, dinamismo e são questionadores sobre aspectos que imponham imobilidade. Esse aspecto é relevante para a compreensão da percepção e comportamento dos alunos diante das ações em que se envolvem.

Para responder alguns interesses da pesquisa, verificou o local de residência dos respondentes, obtendo os dados de: $76 \%$ dos homens residentes na capital, $16 \%$ no interior e $8 \%$ na Grande Aracaju. Já as alunas residem: 47\% na capital, 28\% no interior e 25\% na Grande Aracaju. Observa-se que o contingente de homens na capital é maior, o que oportuniza mais proximidade 
com as atividades desenvolvidas na universidade e, também, no órgão representante da classe, localizado na capital. Esse aspecto é relevante para a análise sobre a mobilidade necessária aos alunos para uma efetiva participação nas ações do movimento estudantil e/ou do órgão de classe.

No bloco inicial, a primeira questão, buscou-se averiguar a opinião dos respondentes sobre o papel que deve ser desempenhado por um centro acadêmico. Ambos os sexos responderem, majoritariamente, com $65,38 \%$ das mulheres e $80 \%$ dos homens, entender tal representação com o papel de defesa de seus direitos acadêmicos e orientação política. Apenas três alunas, do total de 104, responderem entender que o papel de um centro acadêmico é orientar os estudantes sobre o mercado de trabalho para a profissão do curso.

Em continuidade neste bloco, perguntou-se aos alunos como eles avaliam a sua participação junto ao centro acadêmico do curso. Com 52,88\% das mulheres e 36\% dos homens a resposta preponderante foi "média, pois não se trata de uma atividade prioritária em minha vida acadêmica". Aqui se demonstra um entendimento culturalmente aceito de que é necessário um grupo para defesa dos direitos, mas o engajamento a esse grupo não toma relevância nos planos acadêmicos dos alunos de Secretariado Executivo na instituição. A resposta "excelente, pois participo das assembleias, incentivo colegas a participarem e contribuo com as discussões" obteve a menor quantidade de respondentes, sendo oito mulheres e cinco homens, dos 129 respondentes.

A questão três do primeiro bloco buscou a avaliação dos alunos sobre a interação do centro acadêmico com os discentes, surgindo como resposta majoritária entre homens e mulheres a avaliação "alta, pois os membros buscam a interação com os estudantes, tanto presencialmente como por meio eletrônico”. Isso reforça a hipótese de que a geração de respondentes compreende as tecnologias como meio de manter o movimento estudantil, mas não dispensando o contato presencial com quem os representa. O uso de tecnologia para a comunicação estudantil passa a compor a dinâmica de transição de estudante a profissional, visto que o ambiente virtual é utilizado no cotidiano para as tarefas da profissão. A avaliação de uma excelente interação entre centro o acadêmico e os discentes obteve $11,53 \%$ das respostas das mulheres e $12 \%$ dos homens. Um fato relevante identificado é o percentual de 34,61\% das mulheres e 16\% dos homens para a resposta "média, pois os estudantes não têm um local de referência para tratar os assuntos com os membros do CA”. Isso remete à análise de que a inexistência de um espaço estudantil provoca rompimento de interação, o que oportuniza lacunas e/ou enfraquecimento no movimento. Os locais referenciam o espaço de um grupo e a ausência deles pode instaurar a desagregação dos membros.

Na questão quatro desse bloco, buscou verificar a avaliação do discente sobre a atuação do centro acadêmico, obtendo $41,34 \%$ das avaliações das mulheres e 36\% dos homens como "razoável,

Revista de Gestão e Secretariado - GeSec, São Paulo, v. 4, n. 3, p 58-82, dez. 2013. 
pois embora tenham ocorrido mudanças positivas entre as gestões, ocorreram muitos momentos de instabilidade na relação com os estudantes". Isso revela o sentimento de descontinuidade de práticas que cedem lugar a não conexão do indivíduo a sua identidade acadêmica, já que o centro acadêmico os representa nas relações com o curso (Hall, 2005).

$\mathrm{Na}$ questão cinco, no formato aberto, averiguou-se a percepção do aluno sobre como deveria ser a relação do centro acadêmico do curso com os demais centros e diretórios da universidade. Por serem livres as respostas, optou-se em buscar similaridades em termos que oportunizassem a categorização de respostas obtendo-se os dados demonstrados na Tabela 1:

Tabela 1 - Percepção sobre como deveria ser a relação do Centro Acadêmico com os demais centros e diretórios.

\begin{tabular}{|c|c|c|c|c|}
\hline RESPOSTAS & MULHERES & \% MULHERES & HOMENS & \% HOMENS \\
\hline $\begin{array}{c}\text { Interação para participação do } \\
\text { curso em ações conjuntas. }\end{array}$ & 2 & 1,92 & 2 & 8 \\
\hline Troca de experiências. & 18 & 17,30 & 3 & 36 \\
\hline $\begin{array}{c}\text { Intencionando a visibilidade do } \\
\text { curso. }\end{array}$ & 43 & 41,34 & 9 & 16 \\
\hline $\begin{array}{c}\text { Parceria, mas com independência } \\
\text { política. }\end{array}$ & 30 & 28,88 & 4 & 28 \\
\hline $\begin{array}{c}\text { Proximidade para fortalecimento } \\
\text { do movimento estudantil. }\end{array}$ & 11 & 10,57 & 7 & 100 \\
\hline Total & 104 & 100 & 25 & 25 \\
\hline
\end{tabular}

Fonte: Elaborado pela autora.

Observa-se que o maior número de respondentes entende que a relação do centro acadêmico com as representações estudantis da UFS deve atender ao propósito de dar visibilidade ao curso, aspecto que deixa adjacente um sentimento de pouco reconhecimento do curso na estrutura educacional. Complementando essa visão dos estudantes, em ambiente interno, buscou-se verificar 
o entendimento deles sobre a percepção da sociedade sergipana em relação à profissão de secretário executivo.

Essa abordagem, da questão seis do segundo bloco do questionário, demonstrou que 55,76 das alunas e $48 \%$ dos alunos entendem que a sociedade sergipana tem um conhecimento limitado sobre a profissão, oportunizando que pessoas de outras formações atuem como secretários executivos. Essa constatação representa um aspecto cultural sentido no âmbito acadêmico que extrapola para o mercado de trabalho, comprometendo, inclusive, a motivação do estudante para investimento na formação. Vê-se, então, a necessidade de fusão entre os projetos pessoais dos estudantes aos projetos coletivos como forma de defesa do campo profissional, legitimado pelo sistema de credenciamento da formação, da regulamentação legal e da representação laboral (Freidson, 1998). A opção "a sociedade empresarial conhece e valoriza a profissão" não recebeu nenhuma resposta do público investigado, o que reforça a análise sobre a busca de uma identidade profissional reconhecidamente valorizada na sociedade. A situação da profissão em Sergipe, em relação aos demais Estados, alvo da questão sete, constatou que 59,61\% das alunas percebem uma situação ruim para a profissão em Sergipe, dado que o mercado é ocupado, em quase a sua totalidade, por indivíduos com outras formações. Já 36\% dos homens entendem que a situação da profissão no Estado é instável, devido à falta de envolvimento político nas questões da profissão, tanto por parte dos estudantes, quanto por parte dos profissionais e sindicato da classe.

Sobre esse aspecto levantado nas respostas dos homens, na questão oito indagou-se aos estudantes o nível de se envolvimento com as discussões da classe secretarial em Sergipe. A pergunta recebeu 38\% das respostas das mulheres como "médio, pois consulto as minhas representações (CA e Sindicato) para me atualizar sobre essas discussões”. Já os homens apontaram em 32\% das respostas que o nível de envolvimento é "baixo, pois entendo que os representantes estudantis e o Sindicato da classe são os que devem se envolver nessas discussões". Nessa questão flagra-se a incoerência sobre a resposta dos homens em relação à questão anterior, pois ao tempo que entendem que a profissão está fragilizada em Sergipe por falta de envolvimento político dos que compõem a classe, apontam a não responsabilidade sobre a situação, atribuindo ações para uma mudança no quadro da profissão na sociedade apenas ao centro acadêmico e órgão representante. Isso denota uma tentativa de isenção sobre os rumos do grupo profissional, em uma espécie de não pertença ao grupo. A interpretação sobre a situação por parte desses respondentes encaminha-se mais para uma postura observadora das estratégias de desenvolvimento da profissão do que para uma postura participativa na busca de soluções comuns ao grupo. Não há, portanto, o desenvolvimento de um quadro de orientação coletiva sobre a constituição de ações para a situação

Revista de Gestão e Secretariado - GeSec, São Paulo, v. 4, n. 3, p 58-82, dez. 2013. 
social no mundo do trabalho (Weller Pfaff, 2010).

Ainda no segundo bloco, a questão nove buscou a opinião dos estudantes sobre quais ações seriam necessários para a consolidação e reconhecimento da profissão na sociedade. As alunas, em $52,88 \%$ responderam que a "criação de leis para a profissão e a fiscalização no mercado", e em 45,19\% "a efetiva atuação de entidades acadêmicas, sindicatos e associações profissionais”. Já os homens priorizaram as ações de "divulgação nas mídias", com 56\% das respostas, seguidas por 48\% também para "a criação de leis e a fiscalização no mercado". O ponto comum entre alunas e alunos é o fato da legislação e fiscalização, o que remete ao âmbito jurisdicional, apontado por Abbott (1988), pelo qual "uma profissão pede à sociedade que reconheça a sua estrutura cognitiva através do direito de exclusividade" (Abbott, 1988, p. 59). Por ser uma questão semiaberta, uma aluna acrescentou como indicação de ação a busca de divulgação da profissão nas empresas, um aluno acrescentou a abertura de concurso e outro, a busca de visibilidade na sociedade. Dessa forma, verifica-se que a análise cultural sobre uma classe ocupacional, não pode se ater ao nível de delimitações formais e conscientes, mas considerar "aquela área mais ampla de sentimentos, atitudes e pressupostos que comumente marcam, de maneira muito característica, a cultura de determina classe ou outro grupo" (Williams, 2008, p. 26).

Fechando o segundo bloco, a questão dez verificou a opinião dos alunos sobre o efeito das leis voltadas para o Secretariado no Estado de Sergipe. Com 53,84\% das respostas das mulheres e $65,21 \%$ das respostas dos homens, os alunos opinaram por um efeito "pouco expressivo, pois não há fiscalização sobre o cumprimento dessas leis". Isso demonstra que os elementos simbólicos acionados pela profissão, como regulamentações e diplomas não legitimam o exercício profissional nem clarificam os seus fundamentos e, assim, deixam de orientá-lo para valores culturais mais elevados, representando em uma perda da autoridade cultural da profissão na sociedade (Abbott, 1988, Freidson, 1998).

No terceiro bloco de questões, buscou-se averiguar a visão dos estudantes sobre a relação das ações do movimento estudantil com o mundo do trabalho, identificando-se, também, o interesse e nível de envolvimento desses sujeitos com projetos para a defesa e construção identitária do campo profissional. A questão onze abordou quais as ações já desenvolvidas pelo centro acadêmico do curso que o estudante considerou ter contribuído para o desenvolvimento do Secretariado em Sergipe. Com $83,65 \%$ das respostas das mulheres e $68 \%$ dos homens, os alunos responderam "a parceria com o Sindicato de classe em atividades para profissionais e estudantes da área". Isso 
denota a intenção da tradução de uma identidade estudantil para uma identidade profissional. A participação dos estudantes em atividades coletivas próximos a profissionais e representantes da classe podem proporcionar processos identitários que oportunizam consolidar raízes ou "traduzilos” para outras concepções. A distinção entre tradição e tradução cultural, feita por Hall aponta para a possibilidade de o indivíduo pertencer "a dois mundos, [ele deve] aprender a habitar, no mínimo, duas identidades, a falar duas linguagens culturais, a traduzir e a negociar entre elas" (2005, p. 89). Neste caso, em momentos coletivos, os alunos preparam a sua tradução identitária de estudantes para profissionais de Secretariado.

A inter-relação entre movimento estudantil e a construção de uma identidade profissional na sociedade, na opinião dos alunos, ficou latente nas respostas da questão doze deste último bloco, recebendo $75 \%$ das respostas das mulheres e $80 \%$ das respostas dos homens de que uma representação estudantil "é importante para auxiliar a organização dos estudantes na defesa de seus interesses, dentro e fora da instituição de ensino". Isso demonstra o movimento estudantil como elemento de reconhecimento de uma classe, dado o entendimento dos próprios alunos de que o universo de ação deles não se limita ao espaço universitário.

Na questão treze, verificou-se o nível de interesse dos alunos na participação de uma representação estudantil, visto terem esses sujeitos, majoritariamente, apontado a relevância das ações de uma organização dessa natureza para ações do reconhecimento da profissão na sociedade. A pergunta foi: "você já fez parte de um grupo de representação estudantil?", oportunizando respostas "sim" ou "não" e solicitando os motivos. Apenas 11,53\% das mulheres já fizeram parte de uma organização estudantil, apontando como o interesse "lutar pelos direitos estudantis". Já 88,47\% das mulheres nunca participaram de representações estudantis, apontando como maior motivo a "falta de tempo". Sobre os homens, $32 \%$ já participaram do movimento estudantil, apontando como maior motivo o desejo de "contribuir para o curso". Os 68\% restantes dos estudantes homens nunca participaram de representações estudantis, mencionando como maior motivo também a "falta de tempo".

Cabe ressaltar que o curso é noturno e a maioria dos estudantes são trabalhadores durante o dia, além do contingente de alunos ser composto por muitos alunos residentes fora da capital. No entanto, ainda permanece majoritário como local de residência de alunas e alunos as cidades de Aracaju e São Cristóvão, locais que oportunizam maior facilidade de deslocamento para a UFS. Esse aspecto deve ser considerado para as análises, tendo em vista que as atividades de um movimento estudantil demandam disponibilidade de tempo e condições de acesso regular para a universidade. Muitos alunos do interior dispõem apenas de ônibus cedido pelas Prefeituras 
Municipais para a UFS, durante os horários noturnos de aula.

Chama a atenção nas respostas dos homens que $12 \%$ tenham apontado que nunca fizeram parte de uma representação estudantil em virtude da "falta de interesse dos colegas", o que denota a não homogeneidade de estratégias do grupo em suas causas nas escolhas e posturas dos estudantes, acabando por influenciar a sua identidade (Hall, 2005). Comprova-se, aqui, as resistências e embates internos nos campos, conforme apontado em Bourdieu (1989).

Na questão quatorze, buscou-se a opinião dos estudantes sobre itens que representassem a relação entre o movimento estudantil, a educação e o trabalho. A resposta majoritária das mulheres, com $83,65 \%$ e dos homens, com $76 \%$ é a de que "o movimento estudantil pode incentivar os estudantes para uma consciência crítica sobre a própria formação e o mercado que irá atuar”. Observa-se, assim, uma relação entre a cultura dos mundos estudantil e do trabalho, proporcionando uma influência na formação identitária e política. O papel do movimento estudantil parece ser compreendido como o organizador de reflexões sobre a formação e as condições que serão enfrentadas pelos estudantes quando egressos. Isto torna a representação estudantil agente de organização da classe secretarial sergipana, ao lado de profissionais e órgão representante da classe no mercado, formando uma tríade na busca do reconhecimento acusado pelos investigados como ainda a ser conquistado no Estado. Apesar dessa indicação, finalmente, na questão quinze, 26,92\% das mulheres entendem que ao nível de organização da classe secretarial sergipana é alto, pois existe integração entre estudantes, profissionais e Sindicato da área. Já as respostas dos homens apresenta a contradição em relação às das mulheres, com 52\% das respostas, eles entendem que o nível de organização é inexistente, pois a "classe é totalmente desunida". Essa mesma opção recebeu $19,23 \%$ das respostas das mulheres.

Dados os índices relevantes de apontamento de uma "classe desunida" cabe a análise sobre a causa dessa impressão entre os estudantes. Um fato emblemático que talvez possa representar tal sentimento estudantil foi a participação na ação promovida pelo centro acadêmico com a manifestação dos alunos na Assembleia Legislativa do Estado de Sergipe em prol da criação de lei que instituiria o Dia do Secretário no Estado de Sergipe. Ocorrida em 28 de abril de 2012, o pleito obteve a aprovação dos parlamentares, representando a busca do reconhecimento sobre a importância da profissão para a sociedade. Das 36 pessoas presentes à manifestação, 26 eram estudantes das turmas ingressantes nos anos de 2009, 2010 e 2011, e três eram docentes do curso da UFS. Não compareceram alunos das turmas ingressantes em 2008, e 2012. A presença majoritária 
entre alunos foi da turma ingressante em 2011. Do grupo profissional compareceram apenas oito secretários, entre eles quatro representantes sindicais. Para um estado que conta com apenas 5,67\% do mercado ocupado regularmente por secretários habilitados diante dos regulamentos legais da profissão (Sabino, Andrade Jr, 2011) a participação pelo reconhecimento na esfera política seria uma ação de interesse do grupo profissional, tendo em vista as articulações que disso poderia provir. Esse quadro proporciona uma interpretação de maior interesse por parte dos estudantes, especialmente os ingressos de 2011, em movimentos de reconhecimento do campo profissional na sociedade, em contrapartida ao baixo interesse de profissionais já atuantes. O descompasso entre a ênfase nesse interesse pode levar a um cenário carente de politização, articulações e fortalecimento das bases do grupo profissional.

Diante das circunstâncias em que a profissão de secretário se vê envolvida no mercado de trabalho sergipano a sua identidade social ainda demanda ações para a consolidação de seu prestígio e legitimação, resultando em um cenário não atrativo para jovens que sobre ela poderiam se interessar. As exigências de uma formação específica e as fronteiras jurisdicionais servem como instrumentos simbólicos que não produzem a segurança sobre a concorrência de outras ocupações sobre o campo secretarial, não, consagrando, assim, o poder profissional (Freidson, 1998; Bourdieu, 1989).

\section{CONSIDERAÇÕES FINAIS}

O movimento estudantil do curso de Secretariado da UFS, que demonstra maior amadurecimento da representação na gestão 2011/2012, mostra-se forte agente nas ações de construção identitária da profissão no mercado, principalmente pelo fato de ser constituído na única formação em nível superior oferecida no Estado. Porém, tal movimento ocorre em descompasso político em âmbito interno, tendo baixo engajamento dos estudantes nas ações que poderiam representar avanços para a visibilidade do curso no âmbito da instituição. O esforço para a busca dessa visibilidade parece voltar-se à sociedade, em um comportamento notadamente interessado na preparação da tradução de um sujeito estudante para um sujeito profissional. Esse aspecto proporciona a aproximação com a representação da classe, o que poderia ser elemento de ajuda mútua para o poder profissional. As associações profissionais representam o corpo organizativo dos conhecimentos, competências e jurisdições de uma profissão, constituindo uma autoridade política sobre ela. Porém o que se observa na realidade secretarial sergipana é a interpretação de que os

Revista de Gestão e Secretariado - GeSec, São Paulo, v. 4, n. 3, p 58-82, dez. 2013. 
esforços nesse sentido são provindos, majoritariamente, do movimento estudantil, que passa, muitas vezes, a assumir a defesa do campo na condição de principal agente nos requerimentos e tomadas de posição na sociedade.

No tripé do sistema de credencialismo profissional: entidades representantes, Estado e profissionais, os estudantes do curso da UFS parecem ser os agentes mais ativos na busca de reconhecimento na sociedade, comprovando-se, assim, que a cultura universitária em seus movimentos estudantis corroboram a construção da identidade profissional do futuro egresso.

A percepção dos estudantes sobre a fragilidade atual da profissão no mercado sergipano, em relação a sua legitimação e valoração nos espaços produtivos, e o reconhecimento por parte deles de que ações em conjunto com a entidade representante no mercado podem contribuir para o desenvolvimento do Secretariado no Estado, vislumbra dimensões para a construção de relações que levem a mudanças do contexto atual.

As subjetividades que envolvem essa construção perpassam por um trabalho de conscientização sobre a concepção de um coletivo, de uma representação, de um movimento e dos compromissos que depreendem aos sujeitos envolvidos. A confluência de escolhas, inclusões e exclusões não bastam para a construção identitária coletiva. Embora a convivência em determinada cultura, seja acadêmica ou profissional, possibilite a interação do indivíduo com valores, práticas e comportamentos desses ambientes, a consciência sobre o partilhar de uma causa, como na defesa de um campo, demanda o comprometimento com o próprio discurso e atitudes que resultem em formas concretas de ações entre o enunciado e o realizado.

Assim, este estudo pretendeu analisar um grupo em particular, considerando-se contribuinte para novos estudos que visem investigar o movimento estudantil como parte de uma cultura acadêmica que implica na tradução e construção da identidade do indivíduo na sociedade, no tocante ao campo profissional escolhido.

Revista de Gestão e Secretariado - GeSec, São Paulo, v. 4, n. 3, p 58-82, dez. 2013. 


\section{REFERÊNCIAS}

Abbott, A. (1988). The system of professions. Chicago: The University of Chicago Press.

André, M. E. D. A. A. (1984) Estudo de caso: seu potencial na educação. Caderno de Pesquisas da Fundação Carlos Chagas. Rio de Janeiro (49), pp. 51-54.

Araújo, M. P. (2007). Memórias estudantis: da fundação da UNE aos nossos dias. Rio de Janeiro, Relume Dumará.

Becker, H. (1970). Sociological Work: method and substance. Chicago: Aldine Publishing Company.

Bourdieu. P. (1997). Os usos sociais da ciência. São Paulo: Unesp.

. (1989). O poder simbólico. Lisboa: Difel.

Brasil. Lei n. 9.394, de 20 de dezembro de 1996. Estabelece as diretrizes e bases da educação nacional. Diário Oficial da União, Brasília, 23 dezembro, 1996, Seção 1, p. 27.833.

. Lei n.7.393, de 30 de maio de 2012. Institui o Dia Estadual da Secretária e do Secretário no Estado de Sergipe. Diário Oficial do Estado, Sergipe, 31 maio, 2012, Seção Poder Executivo, p. 2.

Carvalho, P. C. (2000). Recursos humanos. Campinas: Alínea.

Centro Acadêmico de XI de Agosto. Histórico. http://www.direito.usp.br/faculdade/caxi08_01.php, recuperado em 2 julho, 2013.

Centro Acadêmico de Secretariado Executivo Maria Lúcia Souza dos Prazeres (2008). Estatuto. São Cristóvão: Arquivo da entidade.

(2013). Relatório de gestão. São Cristóvão: Arquivo da entidade.

Cervo, A. L., Bervian, P. A. (1996). Metodologia científica. São Paulo: Makron Books.

Dubar, C. (1997). A socialização: a construção das identidades sociais e profissionais. Porto: Porto Editora Ltda.

Federação Nacional das Secretárias e Secretários (2010). Estatuto. Brasília: Arquivo da entidade. 
Freidson, E. (1998). Renascimento do profissionalismo: teoria, profecia e política. São Paulo: Universidade de São Paulo.

Freitas , L. F Souza, M. J. (2012). A percepção dos alunos do curso de Administração da PUC Minas campus Poços de Caldas sobre o Diretório Acadêmico de Administração Peter Drucker. Revista Gestão e Conhecimento, 1, (7), março-junho.

Gamboa, S. S., Santos Filho, J. C. dos. (2009). Pesquisa Educacional: quantidade-qualidade. São Paulo: Cortez.

Gil, A. C. (2008). Métodos e técnicas de pesquisa social. São Paulo: Atlas.

Godim, S. M. G. (2002). Perfil profissional e mercado de trabalho: relação com a formação acadêmica pela perspectivas dos estudantes universitários. Revista Estudos de Psicologia, 7, (2), p. 299-309.

Guimarães, S. (2012, abril 10). Secretariado da UFS. Jornal do Dia, Caderno Sociedade, p. 12.

Hall, S. (2005). A identidade cultural na pós-modernidade. Rio de Janeiro: DP \&A.

Hughes, E. (1981). Men and their work. Westport: Greenwood Press Publishers.

Johnson, T. (1972). Professionalisation and professionalism. Profession and Power, Studies in Sociology (pp. 19-38). Londres: Macmillan.

Lancaster, L. C. \& Stillman (2011). D. O Y da questão: como a geração Y está transformando o mercado de trabalho. São Paulo: Saraiva.

Larson, M. S. (1977). The rise of professionalism. Berkeley: University of California Press.

Poerner, A. J. (1979). O poder jovem. Rio de Janeiro: Civilização Brasileira S.A.

Rosa. M. I. (1990). Ensino superior: ascensão ou redenção. Cadernos de Pesquisa, São Paulo (74), 57-61.

Rudio, F. V. (2010). Introdução ao projeto de pesquisa científica. Rio de Janeiro: Vozes.

Sabino, R. F. \& Andrade Jr., J. A. (2011). Secretariado: formação e mercado no Estado de Sergipe. Revista Gestão e Secretariado, 1 (2), 6-31. 
Severino, A. J. (2009). Metodologia do trabalho científico. São Paulo: Cortez.

Sindicato das Secretárias e Secretários do Estado de Sergipe (1991). Estatuto. Aracaju: Arquivo da entidade.

Strauss, L. A. (1992). La trame de la négociation: sociologie qualitative et interactionnisme. Paris: L'Harmattan.

Universidade Federal de Sergipe (2006). Resolução 041. Aprova a criação do curso de Secretariado Executivo. Sergipe: Conselho Universitário [CONSU].

Thompson, E. P. (1981). A miséria da teoria. Rio de Janeiro, Zahar Editores.

Weller, W., Pfaff, N. (2010). Metodologias da pesquisa qualitativa em educação: teoria e prática. Rio de Janeiro: Vozes.

Williams, R. (2008). Cultura. São Paulo: Paz e terra.

Yin, R. K. (2001). Estudo de caso, planejamento e métodos. São Paulo: Bookman. 